\title{
Excess of activating killer cell immunoglobulin-like receptors and lack of HLA-Bw4 ligands: A two-edged weapon in chronic fatigue syndrome
}

\author{
ANNAMARIA PASI $^{1 *}$, SARA BOZZINI $^{3 *}$, NICOLETTA CARLO-STELLA $^{3}$, MIRYAM MARTINETTI $^{1}$, \\ STEFANO BOMBARDIERI ${ }^{4}$, ANNALISA DE SILVESTRI ${ }^{2}$, LAURA SALVANESCHI $^{1}$ and MARIACLARA CUCCIA ${ }^{3}$ \\ ${ }^{1}$ HLA Laboratory, Immunohaematology and Transfusion Center; ${ }^{2}$ Biometrics Unit, Fondazione IRCCS \\ Policlinico San Matteo; ${ }^{3}$ Immunogenetics Laboratory, Department of Genetics and Microbiology, \\ University of Pavia, Pavia; ${ }^{4}$ Rheumatology Division, S. Chiara Hospital, Pisa, Italy
}

Received November 4, 2010; Accepted February 22, 2011

DOI: $10.3892 / \mathrm{mmr} .2011 .447$

\begin{abstract}
Chronic fatigue syndrome (CFS) is an inflammatory disease of unknown aetiology. Researchers have proposed infectious, neurological and immunological causes of this syndrome. Recently, the xenotropic murine leukemia virusrelated virus was detected in $67 \%$ of patients with CFS in a US study. This observation is in agreement with one ascertained aspect of the disease: a decreased efficiency in NK cell lytic activity in CFS patients. Here, we analyzed the genomic polymorphism of killer cell immunoglobulin-like receptors (KIRs) and their HLA class I cognate ligands in patients with certified CFS. An excess of KIR3DS1 was found in CFS patients with respect to controls, as well as an increased frequency of the genotype missing KIR2DS5. Forty-four CFS patients and 50 controls also underwent genomic typing for the HLA-ligands. In the patients, a great proportion of KIR3DL1 and KIR3DS1 receptors were found to be missing their HLA-Bw4 $4^{\text {Ile80 }}$ binding motif. We hypothesize that an excess of KIR3DS1, combined with an excess of ligand-free KIR3DL1 and KIR3DS1 receptors, may hamper the clearance of a pathogen via NK cells, thus favouring the chronicity of the infection.
\end{abstract}

\section{Introduction}

Chronic fatigue syndrome (CFS) is a debilitating disease characterized by chronic post-exertional fatigue of at least

Correspondence to: Professor Mariaclara Cuccia, Immunogenetics Laboratory, Department of Genetics and Microbiology, University of Pavia, Via Ferrata 1, 27100 Pavia, Italy

E-mail mariaclara.cuccia@unipv.it

*Contributed equally

Key words: Chronic Fatigue Syndrome, HLA class I ligands, killer cell immunoglobulin-like receptors a 6-month duration that is not resolved with rest, and by the preclusion of other known diseases which cause its symptoms. The most widely used classification criteria are those established by Fukuda in 1994, although efforts have been made to update these (1-4). The diagnosis of CFS is based on a constellation of symptoms and clinical indicators, as no pathognomonic tests are available. The epidemiology of CFS has been investigated and has been found to include a higher prevalence in women than in men and among individuals between the ages of 18-50 years, with little distinction between socio-economic classes, and a prevalence of $0.5 \%$ in the US (5-7).

Differences in the onset of symptoms (acute or gradual; after a viral infection such as influenza or mononucleosis or without any prodromal episode), the course of the disease (cyclic, steady or slowly worsening, or with gradual improvement until normal health is restored) and the frequent psychiatric and allergic comorbidity suggest that CFS has different aetiologies. Researchers have proposed infectious, neurological or immunological causes for the syndrome.

A number of viruses, such as enterovirus, Epstein Barr virus and herpesvirus, have been implicated as possible causes of CFS, suggesting an underlying immune deficiency (8). In a recent study, the retrovirus xenotropic murine leukemia virusrelated virus (XMRV) was detected by American researchers in the blood cells of patients with CFS (9). This finding was not confirmed in another set of patients originating from the UK $(10,11)$. Population genetic disparities and different pathogenic repertoire may explain why XMRV was not detected in the DNA from UK patients. Preliminary data show that in our Italian population, $39 \%$ of patients and $4.9 \%$ of controls present the retrovirus (unpublished data). The debate is still ongoing, and several research groups are evaluating the possible role of viruses in CFS (12-14). However, a retroviral infection is a particularly attractive possibilty, suggesting an involvement of the host's genetic profile in disease evolution.

A review of the literature has excluded any macroscopic abnormalities in immune cell counts, but there is controversy regarding other aspects of immune system function (15). Our data revealed a pro-inflammatory genotype in patients 
with CFS, with a highly significant increase in TNF- $\alpha$ high producers and a significant decrease in IFN- $\gamma$ low producers compared to a population of healthy controls (16). Therefore, in a recent study (17), we evaluated the presence of autoantibodies in order to elucidate the underlying genetic and immunologic factors contributing to the pathogenesis of CFS A high prevalence of anti-endothelial and anti-neuronal cell antibodies was observed. By contrast, anti-NMDA antibodies were not detected in any of the patients. Moreover, we studied the HLA class II gene DRB1 and two polymorphisms of the RAGE gene promoter (18) in association with CFS, and found notable RAGE-HLA DRB1 haplotypes in patients with this syndrome, suggesting an involvement of the MHC region.

Researchers have additionally found two other factors altered in the immune system of CFS patients: increased expression of $\mathrm{CD}_{28} 8^{+} \mathrm{T}$ lymphocytes and decreased NK cell function (19). NK cells play an essential role at the interface between innate and adaptive immunity. Under normal conditions, through the inhibitory subset of killer immunoglobulin-like receptors (KIRs) expressed on their surface, NK cells recognize self MHC class I molecules (KIR-ligands) on the cell surface, and send an inhibitory signal to avoid the elimination of normal cells. However, when KIRs encounter a damaged cell with missing or underexpressed MHC class I molecules, NK cells are not inhibited and proceed to kill the damaged cell. This concept is known as the missing-self hypothesis (20). The performance of NK cells is guaranteed by properly functioning HLA-KIR interaction, and we suspect a dysregulation at this level in CFS. Therefore, we analysed variability in the presence/absence of KIRs genes and HLA class I ligands in an Italian population to investigate this polymorphism, which is a possible cause of NK cell lytic dysfunction in CFS.

\section{Materials and methods}

Subjects. Patients were recruited through three Italian referral Centres for CFS (Oncologic Reference Center, Aviano, Professor U. Tirelli; Department of Infectious Diseases, University of Chieti, Professor E. Pizzigallo; Department of Rheumatology, University of Pisa, Dr L. Bazzichi) Only patients with a certified diagnosis of CFS were enrolled. A questionnaire was used to re-confirm the diagnosis and to exclude any other possible causes of fatigue based on symptom referral, lab tests and personal/family histories of immune or hereditary disease. A biological bank of peripheral blood, mRNA, serum and red blood cells from CFS patients was established at the Department of Genetics and Microbiology, University of Pavia, as previously described (7).

The controls comprised 217 healthy individuals recruited in Italy whose immunogenetic data have been reported in the literature (21).

Approval for the study was obtained from the Ethics Committee of the University of Pavia.

KIR typing. In 46 randomly selected patients, KIR molecular typing was conducted using the polymerase chain reaction-sequence specific primers (PCR-SSP) technique with a commercial kit (Pel-Freez, Brown Deer, WI, USA) previously validated in an Italian collaborative study of 21 immunogenetics laboratories (21). PCR amplification parameters were as follows: $1 \mathrm{~min}$ at $96^{\circ} \mathrm{C} ; 30$ cycles of $20 \mathrm{sec}$ at $94^{\circ} \mathrm{C}, 20 \mathrm{sec}$ at $63^{\circ} \mathrm{C}, 90 \mathrm{sec}$ at $72^{\circ} \mathrm{C}$; then the temperature was brought to $4^{\circ} \mathrm{C}$.

HLA-class I ligand typing. In 44 CFS patients and 50 randomly selected controls, KIR ligand genotyping was conducted using PCR-SSP with a commercial kit (Olerup SSP AB, Hasselstigen, Saltsjobaden, Sweden). Specifically, this kit allowed for the investigation of the presence of the polymorphisms HLA-Cw ${ }^{\text {asparagine80 }}$, HLA-Cw ${ }^{\text {lysine80 }}$, HLA-B ${ }^{\mathrm{Bw} 4+\text { threonine80, }}$ HLA-B ${ }^{\mathrm{Bw} 4+i s o l e u c i n e 80}$ and HLA-A ${ }^{\mathrm{Bw4+}}$. PCR amplification parameters were as follows: 2 min step at $94^{\circ} \mathrm{C} ; 10$ cycles of $10 \mathrm{sec}$ at $94^{\circ} \mathrm{C}$, then $60 \mathrm{sec}$ at $65^{\circ} \mathrm{C} ; 20$ cycles of $10 \mathrm{sec}$ at $94^{\circ} \mathrm{C}$, then $50 \mathrm{sec}$ at $61^{\circ} \mathrm{C}$, then $30 \mathrm{sec}$ at $72^{\circ} \mathrm{C}$; the temperature was then brought to $4^{\circ} \mathrm{C}$.

The results were read on ready-to-use precasting gels containing ethidium bromide and $2 \%$ agarose under a UV transilluminator.

Statistical analysis. Data analysis was conducted taking into account single KIR genes, KIR genotypes, HLA-ligand motifs and KIR-HLA ligands in CFS patients and controls. Differences were evaluated by the $\chi^{2}$ or Fisher's exact test. Bonferroni correction was also applied considering the number of independent comparisons performed, and the corrected $p$-value $\left(p_{c}\right)$ was calculated. Two-point linkage disequilibrium among KIR genes was also considered, and the degree of linkage disequilibrium was expressed with D' statistics measuring the standard deviation from a random association between two alleles at different loci, calculated from the difference $(\Delta)$ between the observed haplotypic frequency and the expected frequency given by the product of the observed allelic frequencies of the two markers: $\Delta=$ $\mathrm{p}_{i j}-\mathrm{p}_{i} \mathrm{p}_{j}$, where $\mathrm{p}_{i j}$ is the frequency of the haplotype having the allele $i$ at the first locus and the allele $j$ at the second locus, and $\mathrm{p}_{i}$ and $\mathrm{p}_{j}$ are the frequencies of alleles $i$ and $j$ respectively. $\mathrm{R}$ was obtained as a ratio between $\Delta$ and $\mathrm{D}_{\max }$; the maximum value $\Delta$ reached given $\mathrm{p}_{i}$ and $\mathrm{p}_{j}$.

\section{Results}

Prevalence of KIR3DS1 carriers among CFS patients. The distribution of 16 KIR genes in 46 Italian CFS patients and in 217 Italian controls is shown in Table I. The activating KIR genes were labelled with an 'S', which stands for short intracellular tail, while the inhibitory KIR genes were labelled with an 'L', which stands for long intracellular tail. Control data were obtained through a national collaborative network in which our group has also participated, and have been published previously (21). We confirmed the presence of the framework KIR2DL4, KIR3DL2 and KIR3DL3 genes in all patients and in $96-100 \%$ of controls.

In terms of the gene content (the presence or absence of one or more KIR genes), the percentage of carriers of more than three activator KIR genes was generally higher in CFS patients (45.7\%) than in controls (35.6\%), though the difference was not significant. The frequency of patients carrying the KIR3DS1 gene was significantly increased with respect to the controls ( 54.3 vs. $35.4 \%$; $\mathrm{OR}=2.16, \mathrm{p}=0.017$ ), although this 
Table I. Distribution of KIR gene carriers in CFS patients and healthy controls.

\begin{tabular}{|c|c|c|c|c|c|}
\hline KIR genes & CFS $(n=46)$ & Controls $(n=217)$ & $\mathrm{p}$-value & OR & $95 \% \mathrm{CI}$ \\
\hline KIR2DL1 & $46(100 \%)$ & $208(95.9 \%)$ & NS & & \\
\hline KIR2DL2 & $24(52.2 \%)$ & $115(53.0 \%)$ & NS & & \\
\hline KIR2DL3 & $44(95.7 \%)$ & $192(88.5 \%)$ & NS & & \\
\hline KIR2DL4 & $46(100 \%)$ & $216(99.5 \%)$ & NS & & \\
\hline KIR2DL5 & $26(56.5 \%)$ & $106(48.8 \%)$ & NS & & \\
\hline KIR3DL1 & $43(93.5 \%)$ & $210(96.8 \%)$ & NS & & \\
\hline KIR3DL2 & $46(100 \%)$ & $217(100 \%)$ & NS & & \\
\hline KIR3DL3 & $46(100 \%)$ & $216(99.5 \%)$ & NS & & \\
\hline KIR2DS1 & $20(43.5 \%)$ & $79(36.4 \%)$ & NS & & \\
\hline KIR2DS2 & $25(54.3 \%)$ & $115(53.0 \%)$ & NS & & \\
\hline KIR2DS3 & $14(30.4 \%)$ & $71(32.7 \%)$ & NS & & \\
\hline KIR2DS4 & $43(93.5 \%)$ & $210(97.2 \%)$ & NS & & \\
\hline KIR2DS5 & $12(26.1 \%)$ & $61(28.1 \%)$ & NS & & \\
\hline KIR3DS1 & $25(54.3 \%)$ & $77(35.5 \%)$ & 0.017 & 2.16 & 1.137-4.119 \\
\hline
\end{tabular}

CFS, Chronic fatigue syndrome; NS, not significant.

result was not significant after Bonferroni correction $\left(\mathrm{p}_{\mathrm{c}}=\mathrm{NS}\right)$. Nevertheless, there was a trend indicating an association between the KIR3DS1 gene and CFS. Thus, we decided to further examine the genotypes.

Prevalence of the genotype bearing all but the KIR2DS5 gene in CFS patients. The presence/absence of the KIR genes was analysed in CFS patients with respect to the controls. To date, almost 40 KIR genotypes (excluding pseudogenes) have been described in the literature. A detailed list of genotype profiles present in both Italian patients and controls, using the numerical classification adopted by Uhrberg in 2002 for Caucasian populations (22), is shown in Table II. The last line, defined as 'other', comprises the unique profiles found in our sample, which have yet to be assigned a classification number as as they have not yet been described in the literature.

The CFS patients presented 19 different genotype combinations whose haplotypes were not unambiguously assessed as family analysis was not undertaken. Of these, 10 have previously been described in Caucasian populations and 7 were found in Italian controls; however, 9 CFS patients and 29 control genotypes have yet to be described in the literature. Using a comparative analysis of KIR genotype frequency, genotype number 7, which contains all but the KIR2DS5 gene, was observed to be significantly more frequent in patients with respect to the controls: 15.2 vs. $3.7 \%(\mathrm{OR}=4.69, \mathrm{p}=0.003$, $\left.\mathrm{p}_{\mathrm{c}}=0.038\right)$.

Negative linkage disequilibrium between KIR3DS1 and KIR2DL5 or KIR2DS5. Two-point linkage analysis between different KIR genes in patients revealed similar results to the controls described in a report by Bontadini et al, and confirms the presence of linkage disequilibrium between certain KIR genes (21). This makes the evaluation of the independent contribution of single KIR genes towards susceptibility or protection from a disease more difficult. The most interesting data are the $\Delta$ values for the KIR3DS1 gene, which was in positive linkage disequilibrium with $\operatorname{KIR} 2 \mathrm{DS} 1 \quad(\Delta=0.012$; $\left.\mathrm{R}=0.039 ; \mathrm{H}=0.248 ; \mathrm{p}=0.001 ; \mathrm{p}_{\mathrm{c}}=0.04\right)$, as in the control population, but in negative linkage disequilibrium with KIR2DL5 $(\Delta=-0.014 ; \mathrm{R}=-0.046 ; \mathrm{H}=0.293 ; \mathrm{p}=0.005)$ and KIR2DS5 $(\Delta=-0.001 ; \mathrm{R}=-0.004 ; \mathrm{H}=0.140 ; \mathrm{p}=0.020)$, in contrast to the controls and contrary to the results expected, since the KIR3DS1, KIR2DL5 and KIR2DS5 genes map very closely in the telomeric part of the KIR region on the long arm of chromosome 19 (23). However, these results were not significant after Bonferroni correction.

No differences between HLA ligand distribution in CFS patients and controls. In the HLA class I molecules, there is a dimorphism that causes a different ligand affinity for different KIR receptors. This dimorphism is located at residue 80 , where isoleucine may be replaced by threonine in the HLA-B molecules and asparagine may be substituted by lysine in the HLA-C dimers. Here, the distribution of the HLA amino acid motifs in 44/46 Italian CFS patients and in 50/217 controls was analysed, in particular the presence of HLA-Cw ${ }^{\text {asparagine80 }}$ (group C1), HLA-Cw ${ }^{\text {lysine80 }}$ (group C2), HLA-B ${ }^{\text {Bw4+threonine80, }}$ HLA-B $^{\text {Bw4+isoleucine80 }}$, HLA-A ${ }^{\text {Bw4+isoleucine80 }}$ Bw4 supertype, all but A-shared Bw4 motifs and isoleucine 80 alone. The distribution of HLA ligand motifs showed no statistically significant difference between patients and controls.

Excess of ligand-free KIR3DS1 and KIR3DL1 in CFS patients. The interaction between HLA ligands and KIR receptors was examined. KIR2DL1 and KIR2DS1 interact with

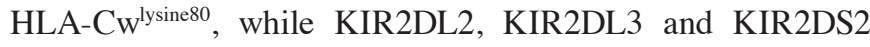
interact with the HLA-CWasparagine80 amino acid motif (24). KIR3DL1 and KIR3DS1 interact with $\mathrm{HLA}^{\mathrm{B}} \mathrm{B}^{\mathrm{Bw} 4+}$ (25), while KIR3DL2 interacts with some HLA-A sequence motifs (26). The various combinatorial frequencies of KIRs with their ligands were determined. Significant results were obtained 


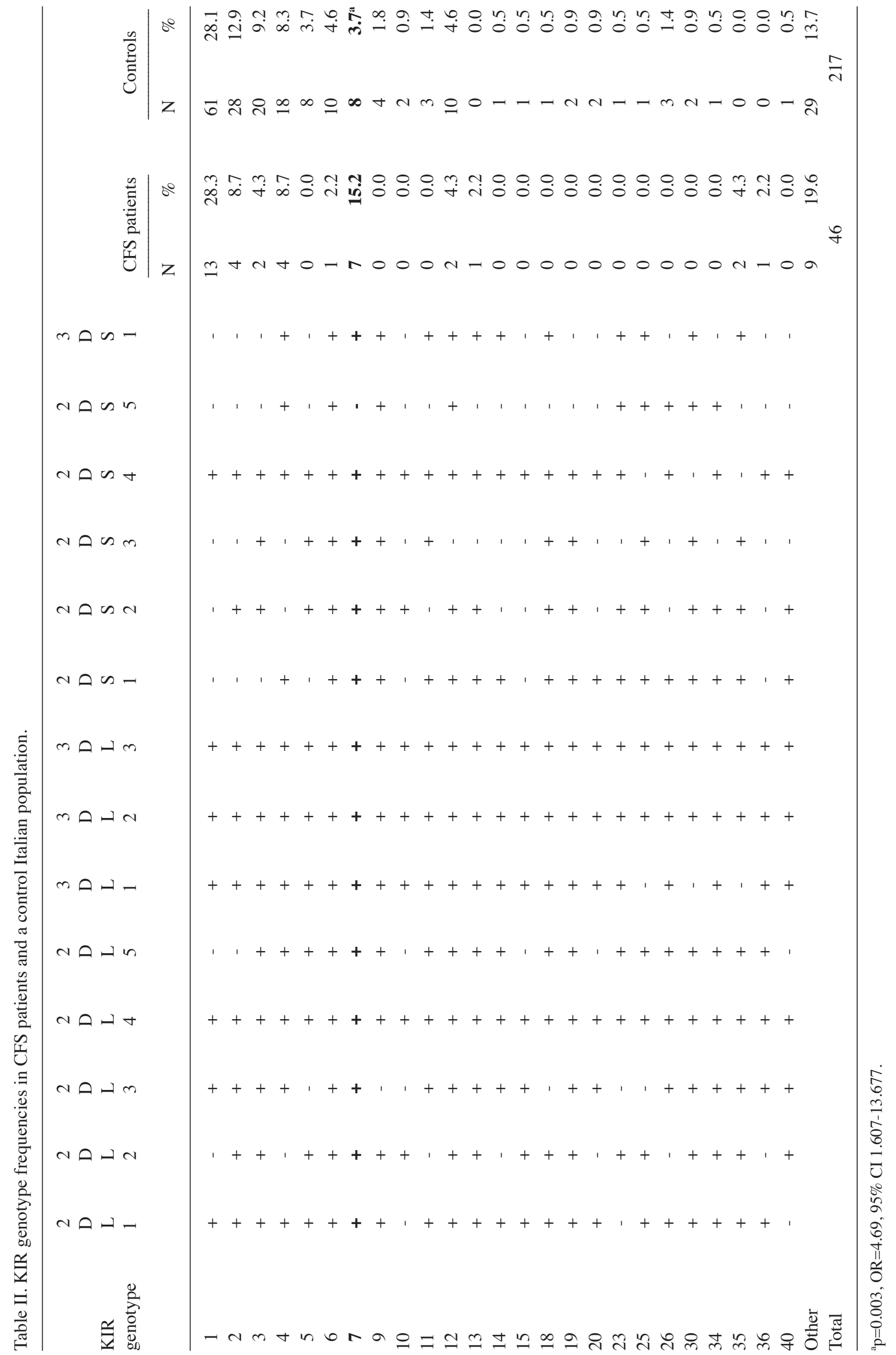


Table III. KIR3DL1/3DS1 and HLA cognate ligands in CFS and in controls.

\begin{tabular}{|c|c|c|c|c|c|c|}
\hline KIR & HLA KIR ligand & CFS $(n=44)$ & Controls $(n=50)$ & $\mathrm{p}$-value & OR & $95 \% \mathrm{CI}$ \\
\hline $\begin{array}{l}\text { 3DL1 } \\
\text { 3DL1 }\end{array}$ & $\begin{array}{l}\text { Bw4 } 4^{\text {Ile } 80} \\
\text { without Bw4 } 4^{\text {Ile } 80}\end{array}$ & $\begin{array}{l}16(36.3 \%) \\
25(56.8 \%)\end{array}$ & $\begin{array}{l}26(52 \%) \\
21(42 \%)\end{array}$ & NS & & \\
\hline $\begin{array}{l}3 \mathrm{DS} 1 \\
3 \mathrm{DS} 1\end{array}$ & 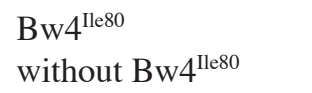 & $\begin{array}{r}7(15.9 \%) \\
17(38.6 \%)\end{array}$ & $\begin{array}{l}12(24 \%) \\
11(22 \%)\end{array}$ & NS & & \\
\hline $\begin{array}{l}\text { 3DL1 } \\
\text { 3DL1 }\end{array}$ & $\begin{array}{l}\text { Bw4 } 4^{\text {Thr80 }} \\
\text { without Bw4 }^{\text {Thr80 }}\end{array}$ & $\begin{array}{l}12(27.3 \%) \\
29(66.0 \%)\end{array}$ & $\begin{array}{l}12(24 \%) \\
35(70 \%)\end{array}$ & NS & & \\
\hline $\begin{array}{l}3 \mathrm{DS} 1 \\
3 \mathrm{DS} 1\end{array}$ & $\begin{array}{l}\mathrm{Bw} 4^{\text {Thr80 }} \\
\text { without Bw4 }^{\text {Thr80 }}\end{array}$ & $\begin{array}{r}9(20.4 \%) \\
15(34.0 \%)\end{array}$ & $\begin{array}{c}4(8 \%) \\
19(38 \%)\end{array}$ & NS & & \\
\hline $\begin{array}{l}\text { 3DL1 } \\
\text { 3DL1 }\end{array}$ & $\begin{array}{l}\mathrm{A}^{\mathrm{Bw} 4 \mathrm{ll} e 80} \\
\text { without } \mathrm{A}^{\mathrm{Bw} 4 \mathrm{ll} \text { e80 }}\end{array}$ & $\begin{array}{l}15(34.0 \%) \\
26(59.0 \%)\end{array}$ & $\begin{array}{l}21(42 \%) \\
26(52 \%)\end{array}$ & NS & & \\
\hline $\begin{array}{l}\text { 3DS1 } \\
\text { 3DS1 }\end{array}$ & $\begin{array}{l}\mathrm{A}^{\mathrm{Bw} 4 \mathrm{lle} 80} \\
\text { without } \mathrm{A}^{\mathrm{Bw} \text { 4Ile80 }}\end{array}$ & $\begin{array}{r}8(18.0 \%) \\
\mathbf{1 6}(\mathbf{3 6 . 0 \%})\end{array}$ & $\begin{array}{r}15(30 \%) \\
8(\mathbf{1 6 \%})\end{array}$ & 0.023 & 3.00 & 1.132-7.946 \\
\hline $\begin{array}{l}\text { 3DL1 } \\
\text { 3DL1 }\end{array}$ & $\begin{array}{l}\text { Ile } 80 \text { motif } \\
\text { without Ile80 motif }\end{array}$ & $\begin{array}{l}23(52.3 \%) \\
\mathbf{3 5}(\mathbf{7 9 . 5 \% )}\end{array}$ & $\begin{array}{l}33(66 \%) \\
26(52 \%)\end{array}$ & 0.005 & 3.59 & 1.432-8.990 \\
\hline $\begin{array}{l}\text { 3DS1 } \\
\text { 3DS1 }\end{array}$ & $\begin{array}{l}\text { Ile80motif } \\
\text { without Ile80 motif }\end{array}$ & $\begin{array}{l}12(27.3 \%) \\
22(50.0 \%)\end{array}$ & $\begin{array}{l}19(38 \%) \\
11(22 \%)\end{array}$ & 0.004 & 3.54 & 1.452-8.657 \\
\hline
\end{tabular}

CFS, Chronic Fatigue Syndrome; NS, not significant.

regarding KIR3DS1/3DL1 and their HLA cognate ligands (Table III). The frequency of individuals with a KIR3DS1 receptor free from its HLA-A ${ }^{\mathrm{Bw} 4+\mathrm{Ile} 80}$ ligand was increased in the CFS group compared to the controls (36 vs. $16 \%$; $\mathrm{p}=0.024$, $\left.\mathrm{OR}=3.0, \mathrm{p}_{\mathrm{c}}=\mathrm{NS}\right)$. The frequency of KIR3DL1 receptors missing of their HLA-ligand (containing the Ile80 motif) was also significantly higher in CFS patients than in controls (79.5 vs. $\left.52 \% ; \mathrm{p}=0.005, \mathrm{OR}=3.59, \mathrm{p}_{\mathrm{c}}=0.04\right)$. Moreover, a significantly increased frequency of individuals with KIR3DS1 lacking their cognate HLA Ile80 motif was observed in the CFS group with respect to the controls (50 vs. $22 \%$; $\mathrm{p}=0.004, \mathrm{OR}=3.55$, $\mathrm{p}_{\mathrm{c}}=0.032$ ).

\section{Discussion}

The KIR gene system consists of a family of polymorphic genes (16 functional and 2 pseudogenes) which map on chromosome $19 \mathrm{q} 13.4$ inside a $1 \mathrm{Mb}$ region known as the leukocyte receptor complex (LRC). Associations between the presence of certain KIR genes and diseases such as rheumatoid arthritis, psoriatic arthritis, scleroderma and p-ANCA positive vasculitis have been described (27-30). It is, however, their specific interaction with HLA ligands that explains their potential involvement in the occurrence of immune-mediated disease, in cancer progression, in the clearance of a pathogen, or in transplant engraftment. Through the interaction between KIR-HLA, NK cells represent the link between innate and adaptive (31).

Based on the results of the present study, we hypothesize that the presence of the activating gene KIR3DS1 may confer susceptibility to CFS. This appears to support a scenario in which the risk of developing CFS is, through a series of events, dependent on the level of NK cell activation.
KIR3DS1 is considered to belong to the lineage of KIR3DL1, and HLA-Bw4 is its ligand. KIR3DS1 is included in the ' $\mathrm{B}$ haplotype' and excluded from the 'A haplotype'. It is known that while the KIR A haplotype has a relatively homogenous genetic organization, characterized by a high degree of inhibitory genes, the $\mathrm{B}$ haplotype is much more variable and contains a greater number of activating genes (36). More activating KIR genes appear to be present in CFS patients: $45.7 \%$ of patients possess more than three activating KIR genes, compared to $35.6 \%$ of controls. Therefore, if we consider the KIR profile alone (i.e., without ligand), it is reasonable to argue that this syndrome is caused by insufficient inhibitory regulation, as has been hypothesized in certain autoimmune diseases, such as insulin-dependent diabetes mellitus (32). A simple interpretation would suggest that KIR3DS1 stimulation of the production of inflammatory cytokines by NK cells contributes to ignite and sustain an inflammatory condition (33).

However, the NK cells in CFS are rather anergic, showing a very low degree of both inhibitory and activating activity (34). The key to interpretation may be in the KIR/HLA interaction rather than in one genetic system alone. In effect, CFS patients seem to present an excess of KIR3DL1 and KIR3DS1 receptors free from their HLA-Bw $4^{\text {isoleucine } 80}$ ligand, suggesting at least two possible scenarios: i) the disease may depend on the presence of the KIR3DL1 inhibitory receptor in the absence of its corresponding ligand, a condition that generates a serious imbalance in the immune response towards stressful events; or ii) the lack of KIR3DL1/KIR3DS1 cognate ligands may be responsible for the low activity of NK cells, which has been demonstrated in patients and is explained here $(19,34)$.

This study was limited by the small patient sample, due mainly to the difficulties in positively diagnosing CFS. The diagnosis of CFS is based on a constellation of symptoms and 
clinical indicators, as no pathognomonic tests are available, and only few medical centres in Italy are capable of diagnosing it. However, our sample size was appropriately powered based upon the observed frequency in our control population.

This study may help elucidate the pathogenesis of CFS. The findings indicate that CFS may be caused by a partially deficient interaction between innate (KIR) and adaptive (HLA) immunity.

\section{Acknowledgements}

The authors wish to thank the patients of the Associazione Malati di CFS and its President, Dr Lorenzo Lorusso, for the support; also, the Foundation Banca del Monte di Lombardia and the current research no. 08058505 of the Foundation IRCCS San Matteo of Pavia for financial support for the study control population.

\section{References}

1. Fukuda K, Straus SE, Hickie I, Sharpe MC, Dobbins JG and Komaroff A: The chronic fatigue syndrome: a comprehensive approach to its definition and study. International Chronic Fatigue Syndrome Study Group. Ann Intern Med 121: 953-959, 1994.

2. Carruthers BM, Jain AK, DeMeirleir K, et al: Myalgic encephalomyelitis/chronic fatigue syndrome: clinical working case definition, diagnostic and treatment protocols. J Chronic Fatigue Syndr 11: 7-11, 2003.

3. Sharpe MC, Archard LC, Banatvala JE, et al: A report - chronic fatigue syndrome: guidelines for research. J R Soc Med 84 118-121, 1991.

4. Reeves WC, Lloyd A, Vernon SD, et al: Identification of ambiguities in the 1994 chronic fatigue syndrome research case definition and recommendations for resolution. BMC Health Serv Res 3: 25-33, 2003.

5. Wessely S, Chalder T, Hirsch S, Wallace P and Wright D: The prevalence and morbidity of chronic fatigue and chronic fatigue syndrome: a prospective primary care study. Am J Public Health 87: 1449-1455, 1997.

6. Jason LA, Richman JA, Rademaker AW, et al: A communitybased study of chronic fatigue syndrome. Arch Intern Med 159: 2129-2137, 1999.

7. Carlo-Stella $\mathrm{N}$ and Cuccia M: Demographic and clinical aspects of an Italian patient population with chronic fatigue syndrome. Reumatismo 61: 285-289, 2009.

8. Devanur LD and Kerr JR: Chronic fatigue syndrome. J Clin Virol 37: 139-150, 2006.

9. Lombardi VC, Ruscetti FW, Das Gupta J, et al: Detection of an infectious retrovirus, XMRV, in blood cells of patients with chronic fatigue syndrome. Science 326: 585-589, 2009.

10. Erlwein O, Kaye S, McClure MO, et al: Failure to detect the novel retrovirus XMRV in chronic fatigue syndrome. PLoS One 5: e8519, 2010 .

11. Groom HC, Boucherit VC, Makinson K, et al: Absence of xenotropic murine leukaemia virus-related virus in UK patients with chronic fatigue syndrome. Retrovirology 7: 10, 2010.

12. Switzer WM, Jia H, Hohn O, et al: Absence of evidence of Xenotropic Murine Leukemia Virus-related virus infection in persons with Chronic Fatigue Syndrome and healthy controls in the United States. Retrovirology 7: 57, 2010.

13. Lloyd A, White P, Wessely S, Sharpe M and Buchwald D: Comment on 'Detection of an infectious retrovirus, XMRV, in blood cells of patients with chronic fatigue syndrome'. Science 328: 825,2010

14. Van der Meer JW, Netea MG, Galama JM and van Kuppeveld FJ: Comment on 'Detection of an infectious retrovirus, XMRV, in blood cells of patients with chronic fatigue syndrome'. Science 328: 825,2010
15. Natelson $\mathrm{BH}$, Haghighi $\mathrm{MH}$ and Ponzio NM: Evidence for the presence of immune dysfunction in chronic fatigue syndrome. Clin Diagn Lab Immunol 9: 747-752, 2002.

16. Carlo-Stella N, Badulli C, De Silvestri A, et al: A first study of cytokine genomic polymophisms in CFS: positive association of TNF-857 and IFNgamma 874 rare alleles. Clin Exp Rheumatol 24: 179-182, 2006.

17. Ortega-Hernandez OD, Cuccia M, Bozzini S, et al: Autoantibodies, polymorphisms in the serotonin pathway, and human leukocyte antigen class II alleles in chronic fatigue syndrome: are they associated with age at onset and specific symptoms? Ann NY Acad Sci 1173: 589-599, 2009.

18. Carlo-Stella N, Bozzini S, De Silvestri A, et al: Molecular study of receptor for advanced glycation endproduct gene promoter and identification of specific HLA haplotypes possibly involved in chronic fatigue syndrome. Int J Immunopathol Pharmacol 22: 745-754, 2009.

19. Klimas NG, Salvato FR, Morgan $R$ and Fletcher MA: Immunologic abnormalities in chronic fatigue syndrome. J Clin Microbiol 28: 1403-1410, 1990.

20. Moretta L, Bottino C, Pende D, Mingari MC, Biassoni R and Moretta A: Human natural killer cells: their origin receptors and function. Eur J Immunol 32: 1205-1211, 2002.

21. Bontadini A, Testi M, Cuccia M, et al: Distribution of killer cell immunoglobulin-like receptors genes in the Italian Caucasian population. J Transl Med 4: 44-52, 2006.

22. Uhrberg M, Parham P and Wernet P: Definition of gene content for nine common group B haplotypes of the caucasoid population: KIR haplotypes contain between seven and eleven KIR genes. Immunogenet 54: 221-229, 2002.

23. Parham P: MHC class I molecules and KIRS in human history, health and survival. Nat Rev Immunol 5: 201-214, 2006.

24. Foley B, De Santis D, Lathbury L, Christiansen F and Witt C: KIR2DS1-mediated activation overrides NKG2A-mediated inhibition in HLA-C C2-negative individuals. Int Immunol 20: 555-563, 2008.

25. Martin MP, Gao X, Lee JH, et al: Epistatic interaction between KIR3DS1 and HLA-B delays the progression to AIDS. Nat Genet 31: 429-434, 2002.

26. Hansasuta P, Dong $\mathrm{T}$, Thananchai $\mathrm{H}$, et al: Recognition of HLA-A3 and HLA-A11 by KIR3DL2 is peptide-specific. Eur J Immunol 34: 1673-1679, 2004.

27. Warrington KJ, Takemura S, Goronzy JJ and Weyand CM: CD4+, CD28- T cells in rheumatoid arthritis patients combine features of the innate and adaptive immune systems. Arthritis Rheum 44: 13-20, 2001

28. Martin MP, Nelson G, Lee JH, et al: Cutting edge: susceptibility to psoriatic arthritis: influence of activating killer Ig-like receptor genes in the absence of specific HLA-C alleles. J Immunol 169: 2818-2822, 2002.

29. Momot T, Koch S, Hunzelmann N, et al: Association of killer cell immunoglobulin-like receptors with scleroderma. Arthritis Rheum 50: 1561-1565, 2004.

30. Miyashita R, Tsuchiya N, Yabe T, et al: Association of killer cell immunoglobulin-like receptor genotypes with microscopic polyangitis. Arthritis Rheum 54: 992-997, 2006.

31. Rajagopalan S and Long EO: Understanding how combinations of HLA and KIR genes influence disease. J Exp Med 201: 1025-1029, 2005

32. Santin I, de Nanclares GP, Calvo B, Gaafar A and Castano L: Killer cell immunoglobulin-like receptor (KIR) genes in the Basque population: association study of KIR gene contents with type 1 diabetes mellitus. Hum Immunol 67: 118-124, 2006.

33. Taniguchi $M$ and Kawabata M: KIR3DL1/S1 genotypes and KIR2DS4 allelic variants in the AB KIR genotypes are associated with Plasmodium-positive individuals in malaria infection. Immunogenetics 61: 717-730, 2009.

34. Caligiuri M, Murray C, Buchwald D, et al: Phenotypic and functional deficiency of natural killer cells in patients with chronic fatigue syndrome. J Immunol 139: 3306-3313, 1987. 